Грудкіна Н. С.

\title{
МАТЕМАТИЧНЕ МОДЕЛЮВАННЯ ПРОЦЕСІВ ХОЛОДНОГО ВИДАВЛЮВАННЯ ІЗ ВИКОРИСТАННЯМ КІНЕМАТИЧНИХ МОДУЛІВ СКЛАДНОЇ КОНФІГУРАЦЇ̈
}

Підвищення конкурентоспроможності продукції галузей машинобудування нерозривно пов'язане з розробкою і освоєнням ефективних ресурсозберігаючих технологій. У зв'язку 3 цим постійно зростає роль процесів обробки металів тиском, в тому числі холодного об'ємного штампування (ХОШ). При цьому процеси видавлювання демонструють стійку тенденцію до збільшення обсягів виробництва точних заготовок та розширення номенклатури штампованих деталей та матеріалів [1]. Перспективним є комбіноване видавлювання (суміщене або послідовне), що з одного боку підвищує технологічні можливості процесів штампування, з іншого характеризується недостатнім освітленням досліджень як силового режиму, так і прогнозування формоутворення напівфабрикату [2-5].

На даний час аналіз впливу технологічних параметрів процесів комбінованого видавлювання $з$ декількома степенями свободи течії металу в основному проведений експериментально та методом скінченних елементів (MCE). Ці дослідження характеризуються відсутністю аналітичних залежностей енергосилових параметрів процесу та величини приростів напівфабрикату [2-5]. На даний час до ефективних теоретичних методів дослідження процесів холодного видавлювання (в тому числі з декількома степенями свободи течії металу) можна віднести енергетичний метод верхньої оцінки $[6,7]$. Одним 3 ключових етапів його застосування можна вважати підбір функцій, що описують кінематично можливе поле швидкості (КМПШ). Важливим $є$ і пошук інструментів спрощення складових енергетичного рівняння, що дозволить отримати приведений тиск у аналітичному вигляді. Це є актуальною задачею перш за все для розрахункових схем процесів, що містять кінематичні модулі складної конфігурації. Ускладнення кінематичних модулів стосуються як форми (прямокутні, трикутні, трапецеїдальні), так і наявності похилої границі у вигляді прямої або деякої кривої. При цьому форма межі може бути задана у вигляді однопараметричного сімейства кривих $z(r, \alpha)$ або у вигляді цілком визначеної функції $z(r)$. В першому випадку параметр $\alpha$ може розглядатися як параметр оптимізації даного кінематичного модуля, в другому випадку такої можливості немає. Однак наявність похилої межі криволінійної форми зазвичай призводить до ускладнення математичного апарату наступних обчислень. Це перш за все стосується визначення потужності сил деформування всередині кінематичного модуля та потужності сил зрізу на поверхні суміжних кінематичних модулів. Перші спроби вирішити проблеми спрощення розрахунків потужності сил деформування стосувалися можливості використання лінеаризації інтенсивності швидкостей деформації [7]. Однак в подальшому виявлена їх неефективність при моделюванні процесів комбінованого радіально-зворотного видавлювання у зв'язку із неможливістю обрати відповідну заміну, єдину у межах всього кінематичного модуля [8]. До ефективних прийомів спрощення розрахунків приведеного тиску деформування можна віднести метод, що грунтується на використанні функцій, що є розв'язком диференціального рівняння, яке дозволяє отримати вираз інтенсивності швидкостей деформації у вигляді, прийнятному для подальшого інтегрування. Таким чином, можливою стає оптимізація функції приведеного зусилля деформування за кінематичними параметрами, що дозволяє в подальшому прогнозувати формоутворення деталі. Однак цей прийом раціонально застосовувати для осьових трапецеїдальних кінематичних модулів з похилою границею у вигляді $T=T(z)$. При цьому для кінематичних модулів із одним ступенем свободи течії металу поділ на класи може бути проведений по відношенню до вісі симетрії (осьові чи неосьові) або за наявності швидкості витікання через похилу межу (внутрішні кінематичні модулі) або ні (в цьому випадку похила межа відображає поверхню контакту заготовки та інструменту). 
При цьому форма інструменту визначає форму похилої межі відповідного кінематичного модуля. Також поділ кінематичних модулів можливий за наявністю однієї чи двох ступенів свободи течії металу всередині кінематичного модуля. Кожний клас (тип) кінематичних модулів має свої особливості використання та потребує дослідження раціональності використання в порівнянні із кінематичними модулями прямокутної форми із відомими складовими $[8,9]$. Особливої уваги потребують саме кінематичні модулі, що відображають особливості конфігурації інструменту (наявність фасок, заокруглень, кромок).

Метою роботи є виявлення особливостей використання кінематичних модулів складної конфігурації та вироблення чітких рекомендацій щодо їх застосування для моделювання процесів холодного видавлювання.

Розглянемо приклади деяких кінематичних модулів складної конфігурації (таблиця 1). Дані кінематичні модулі з одним ступенем свободи течії металу (одна вхідна та вихідна швидкість) можуть використовуватися для відображення конфігурації інструменту.

Таблица 1

Форма та КМПШ кінематичних модулів

\begin{tabular}{|c|c|}
\hline Форма кінематичного модуля & КМПШ кінематичного модуля \\
\hline & де $z(r)=-\left(r-R_{1}\right) \cdot \operatorname{tg} \alpha, z^{\prime}(r)=-\operatorname{tg} \alpha=-\frac{h}{R_{1}}$ \\
$V_{r 3 a}=\frac{V_{0}(z) r}{2(H-z(r))}$.
\end{tabular}

При цьому дані модулі демонструють перехід течії металу від прямого до радіального напрямку (кінематичний модуль 3a) або навпаки (кінематичний модуль 3b). Побудовані КМПШ даних кінематичних модулів є досить складними з точки зору отримання приведеного тиску деформування в аналітичному вигляді. Отримати величину потужності сил деформування в аналітичному вигляді вдається тільки завдяки використання прийомів спрощення величини інтенсивності швидкостей деформації. Нераціональність використання різних видів лінеаризації даної величини було продемонстровано в попередніх дослідженнях. Для отримання величини потужності сил деформування в аналітичному вигляді використовуємо верхню оцінку: 
$\iiint_{V} \dot{\varepsilon}_{i 3 a}^{2} d V=-\frac{\pi V_{0}^{2}}{18 k}\left(12+\operatorname{tg}^{2} \alpha\right)\left[\begin{array}{l}R_{1}+(3 C-A) \ln \left(\frac{H}{H-h}\right)-3 C^{2}\left(\frac{1}{C}+\frac{\operatorname{tg} \alpha}{H}\right)-\left(\frac{1}{C}+\frac{\operatorname{tg} \alpha}{H}\right)(B-2 A C)- \\ -\frac{B C}{2}\left(\frac{\operatorname{tg}^{2} \alpha}{H^{2}}-\frac{1}{C^{2}}\right)-\frac{C^{3}-A C^{2}}{2}\left(\frac{\operatorname{tg}^{2} \alpha}{H^{2}}-\frac{1}{C^{2}}\right)\end{array}\right]$,

де $A=\frac{6(h-H)\left(6+\operatorname{tg}^{2} \alpha\right)}{\left(12+\operatorname{tg}^{2} \alpha\right) \operatorname{tg} \alpha}, B=\frac{9(H-h)^{2}\left(4+\operatorname{tg}^{2} \alpha\right)}{\left(12+\operatorname{tg}^{2} \alpha\right) \operatorname{tg}^{2} \alpha}, C=R_{1}-\frac{H}{\operatorname{tg} \alpha}$.

Таким чином отримано із врахуванням (1), маємо:

$$
N_{d 3 a} \leq \sigma_{S} \sqrt{V_{3 a} \cdot \iiint_{V} \dot{\varepsilon}_{i 3 a}{ }^{2} d V},
$$

де $V_{3 a}=\frac{\left(3\left(H-R_{1} \operatorname{tg} \alpha\right)+2 R_{1} \operatorname{tg} \alpha\right) R_{1}^{2}}{3} \pi-$ об'єм області кінематичного модуля За.

Потужності сил зрізу на поверхні входу $N_{c 3 a \rightarrow}$ для даного кінематичного модуля із верхнім суміжним модулем $2\left(V_{z 2}=-V_{0}, V_{r 2}=0\right)$ мають вигляд:

$$
N_{c 3 a \rightarrow}=\frac{\pi \sigma_{S} V_{0}}{\sqrt{3} \cdot \operatorname{tg} \alpha}\left[\frac{R_{1}^{2}}{2}+\left(R_{1}-\frac{H}{\operatorname{tg} \alpha}\right) R_{1}+\left(R_{1}-\frac{H}{\operatorname{tg} \alpha}\right)^{2} \ln \left(\frac{H}{H-h}\right)\right] .
$$

Якщо даний кінематичний модуль розглядаємо як модуль, що межує з інструментом на похилій межі $z(r)$, то потужність сил тертя набуває вигляду:

$$
N_{t 3 a}=2 \mu_{s} \cdot\left(1+\operatorname{tg}^{2} \alpha\right) \cdot N_{c 3 a \rightarrow},
$$

де $\mu_{S}-$ коефіцієнт тертя $\left(0 \leq \mu_{S} \leq 0,5\right)$.

Повна величина потужності сил зрізу на межі кінематичних модулів 3a та 3b приймає вигляд:

$$
N_{c 3 a_{-} 3 b}=\frac{\pi \sigma_{S} R_{1} H V_{0}}{\sqrt{3}}\left|\frac{R_{1}^{2}}{R_{2}^{2}-R_{1}^{2}}-\frac{(\operatorname{tg} \alpha+k) R_{1}}{2 H}-1\right|
$$

Таким чином, можна отримати величину приведеного тиску деформування даного кінематичного модуля з урахуванням верхньої оцінки потужності сил деформування (2), тертя (4) та зрізу із суміжними модулями (3) та (5) у вигляді:

$$
\Delta \bar{p}=\frac{N_{d 3 a}+N_{c 3 a \rightarrow}+N_{c 3 a_{-} 3 b}+N_{t 3 a}}{\pi \sigma_{s} V_{0} R_{1}^{2}} .
$$

Використовуючи приведений тиск деформування модуля 3а із урахуванням суміжного 3b, можна дослідити можливості оптимізації форми інструменту (кута нахилу протипуансону $\alpha$ ) 
для процесів видавлювання із розворотом течії металу від вісі до радіального видавлювання за різних співвідношень та умов тертя (рис. 1).

Аналіз впливу умов тертя на поверхні контакту заготовки та протипуансону на величину приведеного тиску визначаємо за відносних геометричних параметрів у вигляді $\bar{R}_{1}=R_{1} / R_{2}, \bar{H}=H / R_{2}, \bar{h}=h / R_{2}$ та $\bar{h}_{2}=h_{2} / R_{2}$ (рис. 1 , a). Величина $\Delta \bar{p}$ зростає із погіршенням умов тертя, для діапазону $\mu_{S}=0 \div 0.24$, дані функції мають точку мінімуму, крім граничного $\mu_{S}=0$. Величина приведеного тиску $\Delta \bar{p}$ збільшується із зменшенням відносної товщини фланцевої зони (рис. 1, б). Вплив відносного геометричного параметра $\bar{H}$ iз збереженням інших геометричних співвідношень процесу деформування є досить значним, оптимальне значення величини $\bar{h}$ зміщується в сторону збільшення. Для достатньо великої товщини $\bar{H}=0.5$ точки мінімуму немає, тобто величина $\bar{h}$, що відповідає оптимальному значенню приведеного тиску, прямує до $\bar{H}$ ( таким чином, кінематичний модуль За вироджується у трикутний кінематичний модуль).
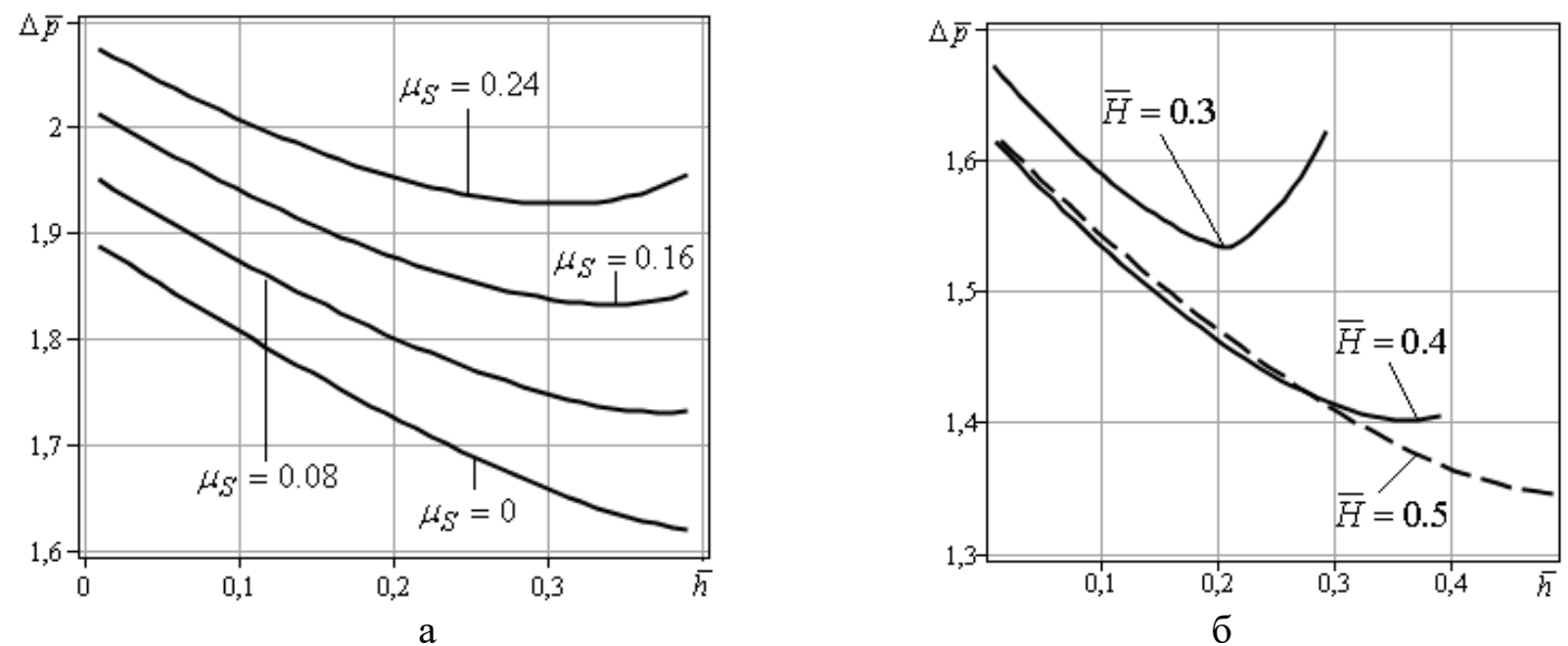

Рис. 1. Залежності величини приведеного тиску деформування $\Delta \bar{p}$ від параметра $\bar{h}$ : а- за різних умов тертя та $\bar{R}_{1}=0.8, \bar{h}_{2}=0.2 ;$ б-за різних $\bar{H}$ та $\bar{R}_{1}=0.7, \bar{h}_{2}=0.2, \mu_{S}=0.16$

Таким чином, розроблений кінематичний модуль За складної форми може бути використаний при моделюванні процесів холодного видавлювання із урахуванням кута нахилу протипуансону. Отриманий вираз приведеного тиску деформування із урахуванням суміжного кінематичного модуля 3b може бути використаний як складова процесу холодного видавлювання із переходом від прямої до радіальної течії. Виявлено можливості використання кута $\alpha$ у якості параметра оптимізації та суттєвий вплив на оптимальне значення $\bar{h}$ відносної товщини фланцевої зони $\bar{H}$. За великих значень $\bar{H}$ можливо виродження трапецеїдального модуля За у трикутний.

\section{ВИСНОВКИ}

Розглянуто осьовий трапецеїдальний кінематичний модуль $3 \mathrm{a}$ із нижньою прямолінійною похилою межею. Одержано величину приведеного тиску деформування із урахуванням суміжного кінематичного модуля трапецеїдальної форми $3 \mathrm{~b}$. Умови тертя та відносна величина товщини фланцевої зони $\bar{H}$ суттєво впливають на можливість оптимізації приведеного тиску за параметром $h$, що характеризує форму протипуансону (кут нахилу $\alpha$ ). Отримані результати можуть бути використані при моделюванні процесів холодного видавлювання із переходом від прямої до радіальної течії. Це сприятиме визначенню оптимальних параметрів конфігурації інструмента та розробці відповідних конструкторськотехнологічних рекомендацій. 


\section{СПИСОК ВИКОРИСТАНОЇ ЛІТЕРАТУРИ}

1. Алиева Л. И. Процессы комбинированного выдавливания и деформирования. Обработка материалов давлением. Краматорск: ДГМА. 2016. 1 (42). С. 100-108.

2. Farhoumand A., Ebrahimi R. Analysis of forward-backward-radial extrusion process. Materials and Design. 2009. 30. 6, pp. 2152-2157. DOI: https://doi.org/10.1016/j.matdes.2008.08.025

3. Noh J., Hwang B.B., Le H.Y. Influence of Punch Face Angle and Reduction on Flow Mode in Backward and Combined Radial Backward Extrusion Process. Metals and Materials International. 2015. 21. 6, pp.1091-1100. DOI: https://doi.org/10.1007/s12540-015-5276-y

4. Choi H. J., Choi J. H., Hwang B. B. The forming characteristics of radial-backward extrusion. J Mater Process Technol. 2001, 113, pp. 141-147. DOI: https://doi.org/10.1016/S0924-0136(01)00703-8

5. Jafarzadeh H., Zadshakoyan M., Sobbouhi E. Abdi. Numerical studies of some important design factors in radial-forward extrusion process. Materials and Manufacturing Processes. 2010. 25, pp. 857-863. DOI: https://doi.org/10.1080/10426910903536741

6. Степанский Л. Г. Расчеты процессов обработки металлов давлением. Москва: Машиностроение. 1979. $215 \mathrm{c}$.

7. Чудаков П. Д. О вычислении мощности пластической деформации. Известия вузов. Машиностроение. 1979. 7. С. 146-148.

8. Hrudkina N., Aliieva L., Abhari P., Kuznetsov M., Shevtsov S. Derivation of engineering formulas in order to calculate energy-power parameters and a shape change in a semi-finished product in the process of combined extrusion. Eastern-European Journal of Enterprise Technologies. 2019. 2. 7 (98), pp. 49-57. DOI: 10.15587/17294061.2019.160585. DOI: https://doi.org/10.15587/1729-4061.2019.160585

9. Hrudkina N., Aliieva L., Abhari P., Markov O., Sukhovirska L. Investigating the process of shrinkage depression formation at the combined radial-backward extrusion of parts with a flange. Eastern-European Journal of Enterprise Technologies. 2019. 2. 5/1 (101), pp. 49-57. DOI: https://doi:10.15587/1729-4061.2019.179232

\section{REFERENCES}

1. Aliieva L.I. Processes of combined plasticity deformation and extrusion. Materials Working by Pressure. Kramatorsk: DSEA. 2016. 1 (42), pp. 100-108. (in Russian).

2. Farhoumand A., Ebrahimi R. Analysis of forward-backward-radial extrusion process. Materials and Design. 2009. 30. 6. pp. 2152-2157. DOI: https://doi.org/10.1016/j.matdes.2008.08.025

3. Noh J., Hwang B.B., Le H.Y. Influence of Punch Face Angle and Reduction on Flow Mode in Backward and Combined Radial Backward Extrusion Process. Metals and Materials International. 2015. 21. 6, pp.1091-1100. DOI: https://doi.org/10.1007/s12540-015-5276-y

4. Choi H.J., Choi J.H., Hwang B.B. The forming characteristics of radial-backward extrusion. J Mater Process Technol. 2001. 113, pp. 141-147. DOI: https://doi.org/10.1016/S0924-0136(01)00703-8

5. Jafarzadeh H., Zadshakoyan M., Sobbouhi E. Abdi. Numerical studies of some important design factors in radial-forward extrusion process. Materials and Manufacturing Processes. 2010. 25. pp. 857-863. DOI: https://doi.org/10.1080/10426910903536741 (in Russian).

6. Stepanskiy L.G. Calculations of metal forming processes. Moscow: Mechanical Engineering. 1979, 215 p.

7. Chudakov P. D. About calculating the power of plastic deformation. Proceedings of universities. Mechanical engineering. 1979. 7, pp. 146-148. (in Russian).

8. Hrudkina N., Aliieva L., Abhari P., Kuznetsov M., Shevtsov S. Derivation of engineering formulas in order to calculate energy-power parameters and a shape change in a semi-finished product in the process of combined extrusion. Eastern-European Journal of Enterprise Technologies. 2019. 2. 7 (98), pp. 49-57. DOI: 10.15587/17294061.2019.160585. DOI: https://doi.org/10.15587/1729-4061.2019.160585

9. Hrudkina N., Aliieva L., Abhari P., Markov O., Sukhovirska L. Investigating the process of shrinkage depression formation at the combined radial-backward extrusion of parts with a flange. Eastern-European Journal of Enterprise Technologies. 2019. 2. 5/1 (101), pp. 49-57. DOI: https://doi:10.15587/1729-4061.2019.179232

Грудкіна Н. С. - канд. техн. наук, докторант ДДМА.

ДДМА - Донбаська державна машинобудівна академія, м. Краматорськ.

E-mail: vm.grudkina@ukr.net 